Supporting Information

\title{
Phosphonate-Derivatized Porphyrins for Photoelectrochemical Applications
}

Animesh Nayak, Subhangi Roy, Benjamin D. Sherman, Leila Alibabaei, Alexander M. Lapides, M. Kyle Brennaman, Kyung-Ryang Wee and Thomas J. Meyer*

Department of Chemistry, University of North Carolina at Chapel Hill, 121 South Road, Chapel Hill, NC 275993290 U.S.A.

*e-mail: tjmeyer@unc.edu 


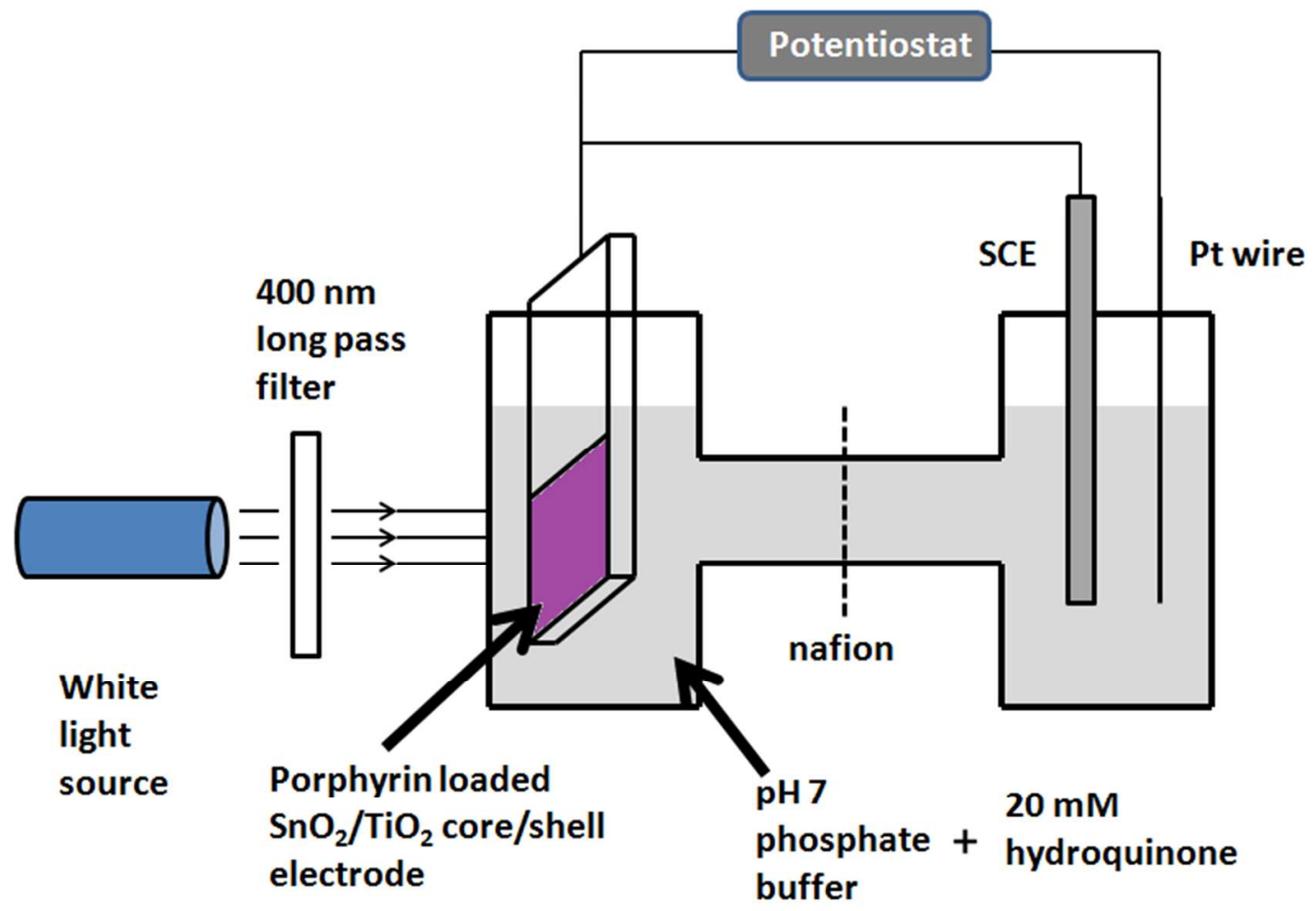

Figure S1. A schematic representation of photocurrent measurement set up 

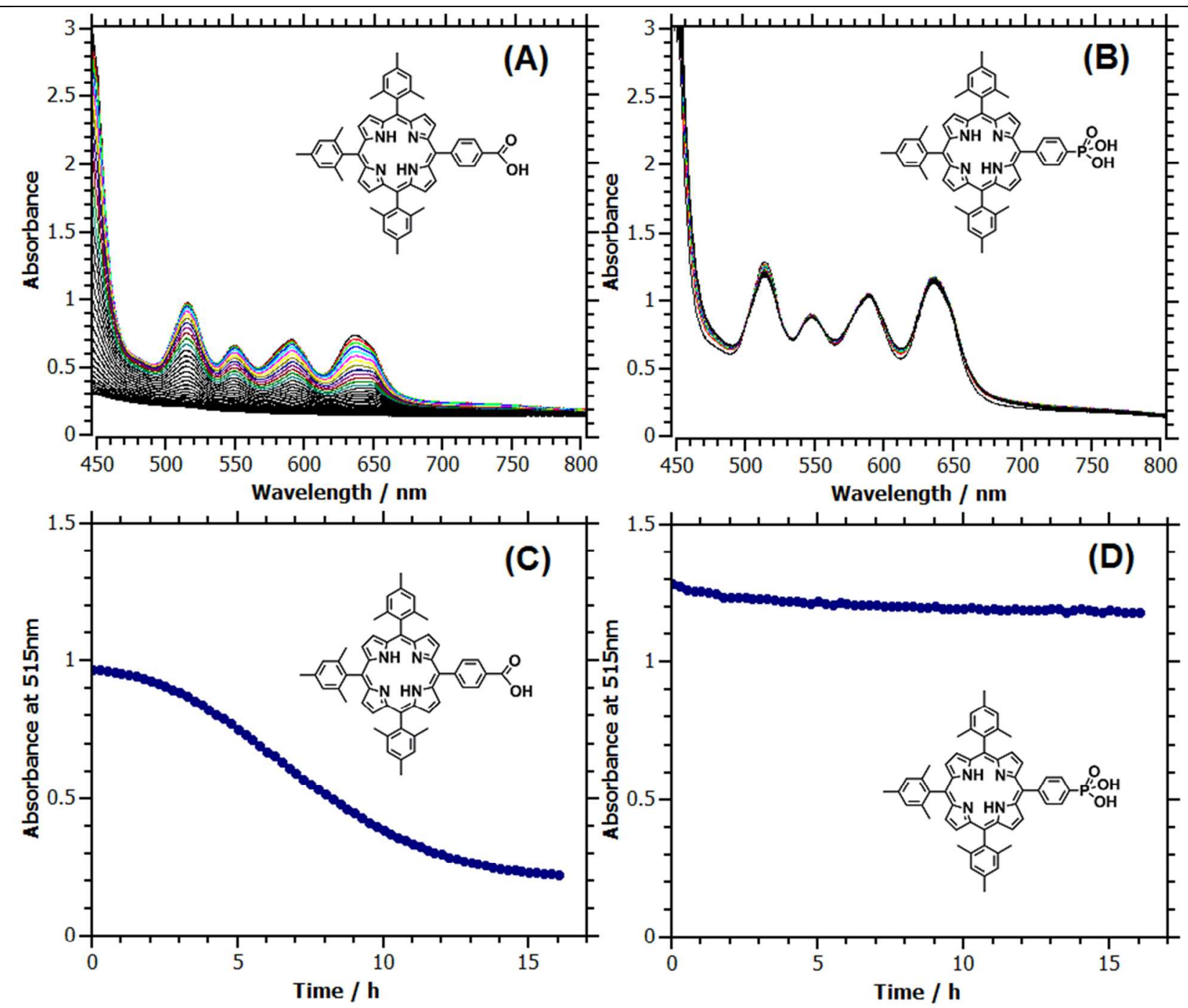

Figure S2: Absorbance changes of carboxylate (A) and phosphonate (B) porphyrin-loaded nano $\mathrm{TiO}_{2}$ slides, continuously irradiated with $455 \mathrm{~nm}$ light $\left(475 \mathrm{~mW} / \mathrm{cm}^{2}\right)$, recorded every $15 \mathrm{~min}$ for $16 \mathrm{~h}$. (C) and (D) shows absorbance change at $515 \mathrm{~nm}$ over time. 

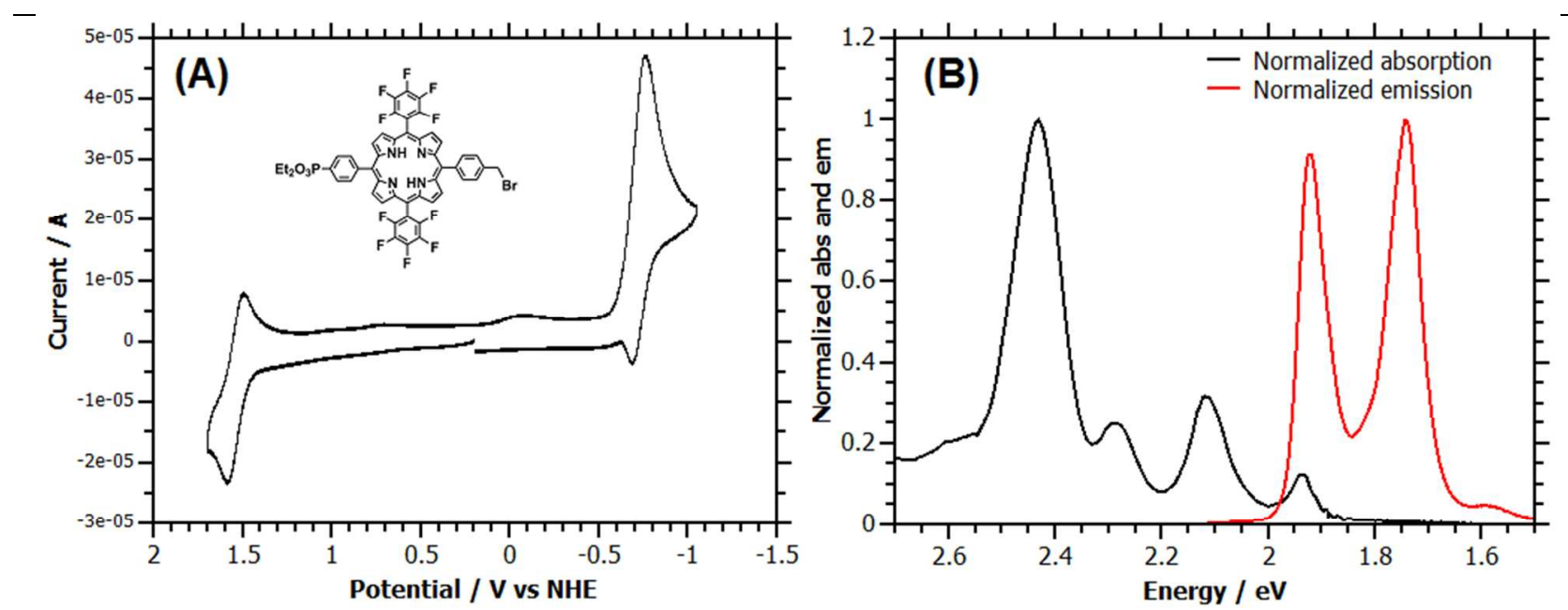

Figure S3. Cyclic voltammetry (A) and cross section of normalized absorption and emission (B) for compound $\mathbf{3 E}$ in solution.
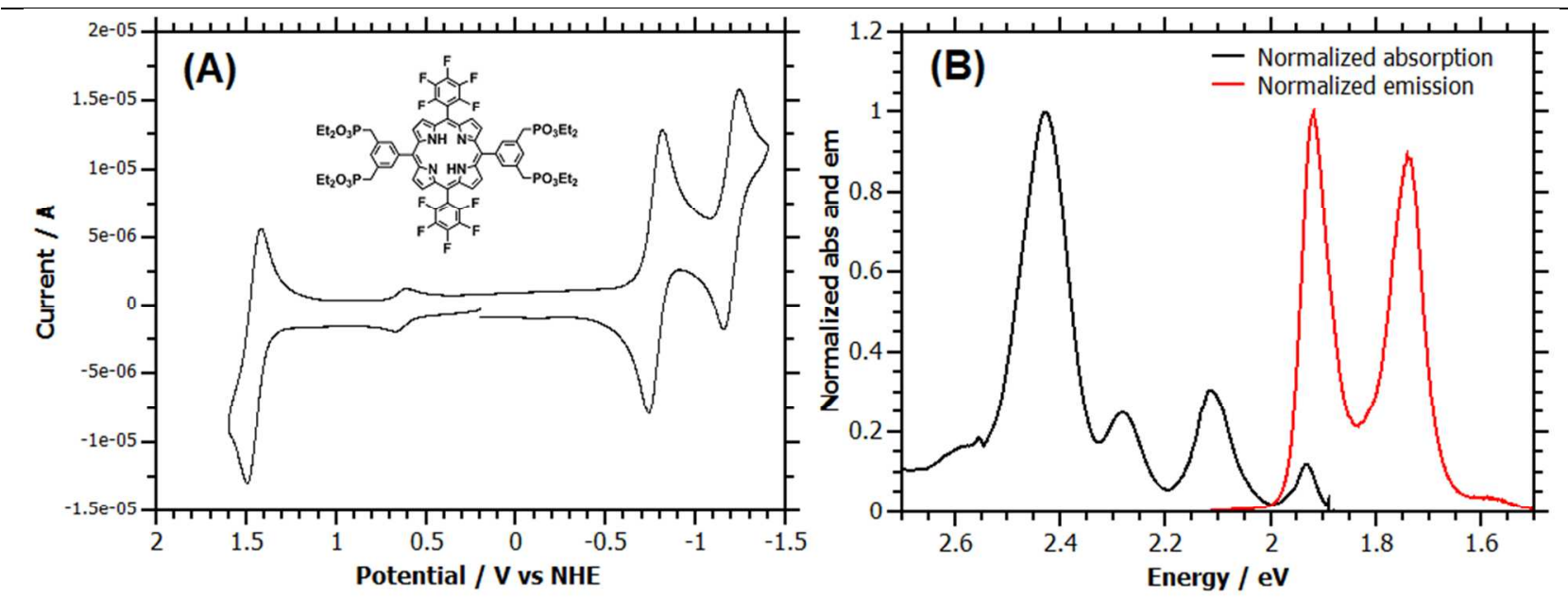

Figure S4. Cyclic voltammetry (A) and cross section of normalized absorption and emission (B) for compound $4 \mathrm{E}$ in solution. 

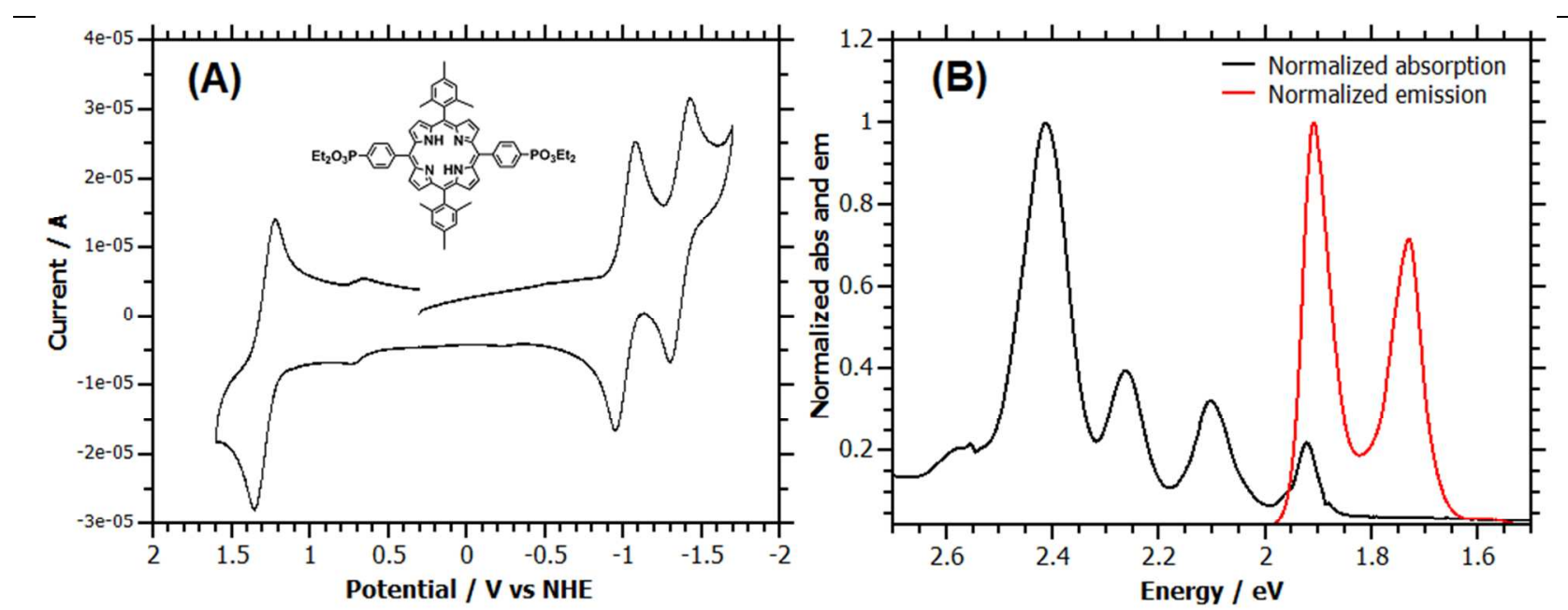

Figure S5. Cyclic voltammetry (A) and cross section of normalized absorption and emission (B) for compound $5 \mathrm{E}$ in solution.
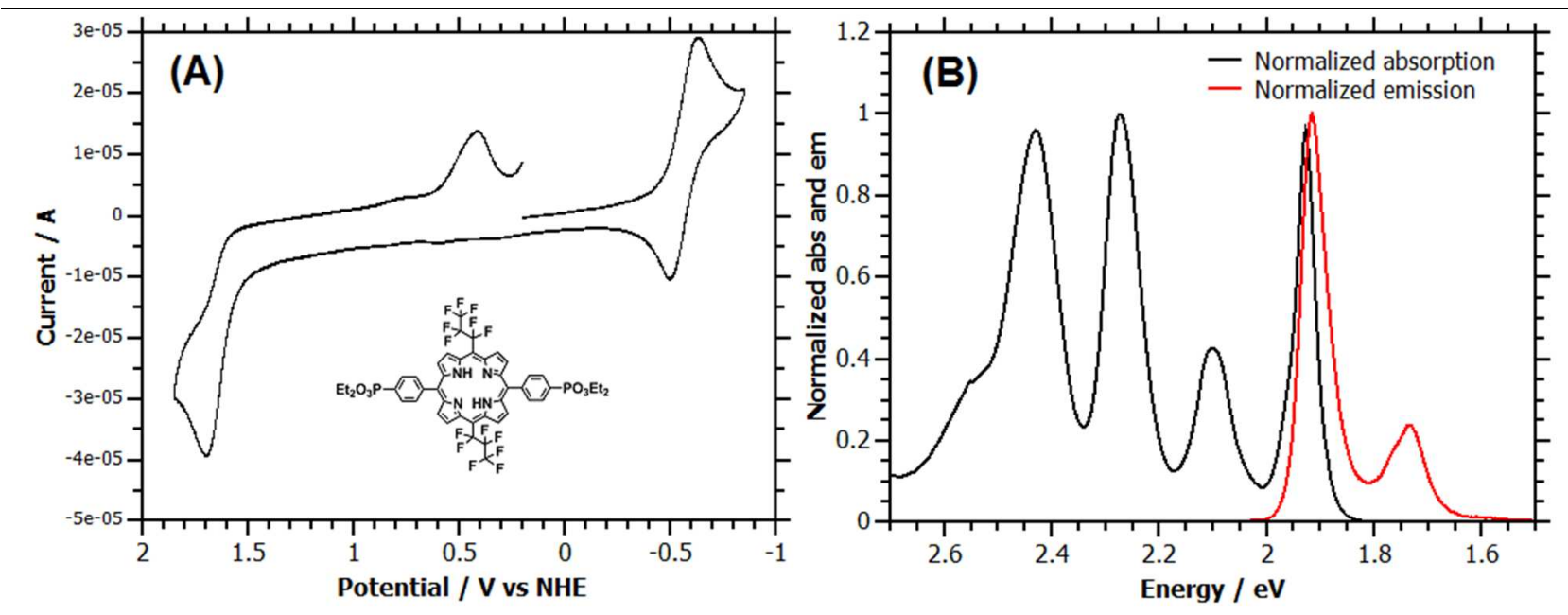

Figure S6. Cyclic voltammetry (A) and cross section of normalized absorption and emission (B) for compound 6E 


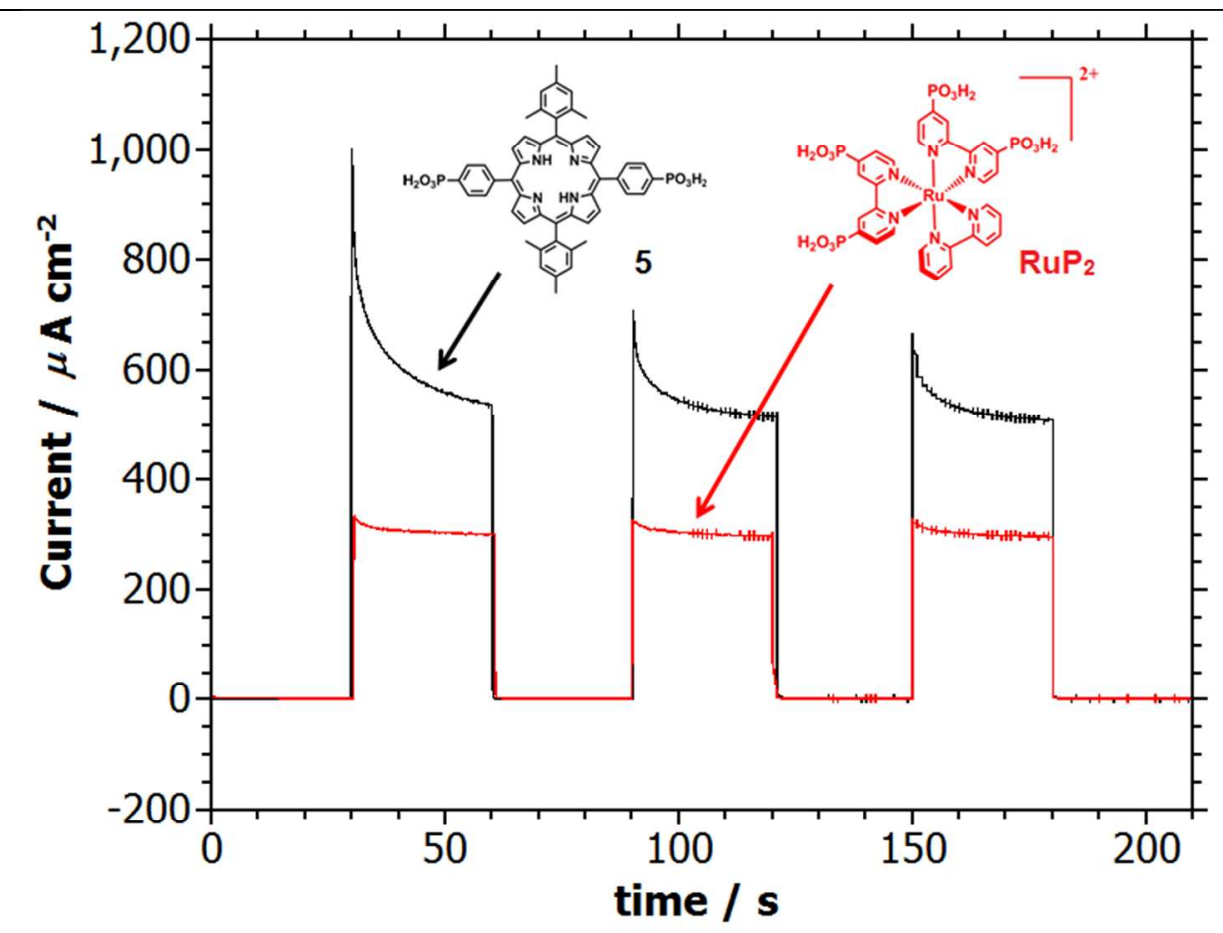

Figure S7. Comparison of photocurrent response of $\mathbf{R u P}_{\mathbf{2}}$ and $\mathbf{5}$ in pH 7 phosphate buffer with $20 \mathrm{mM}$ hydroquinone 

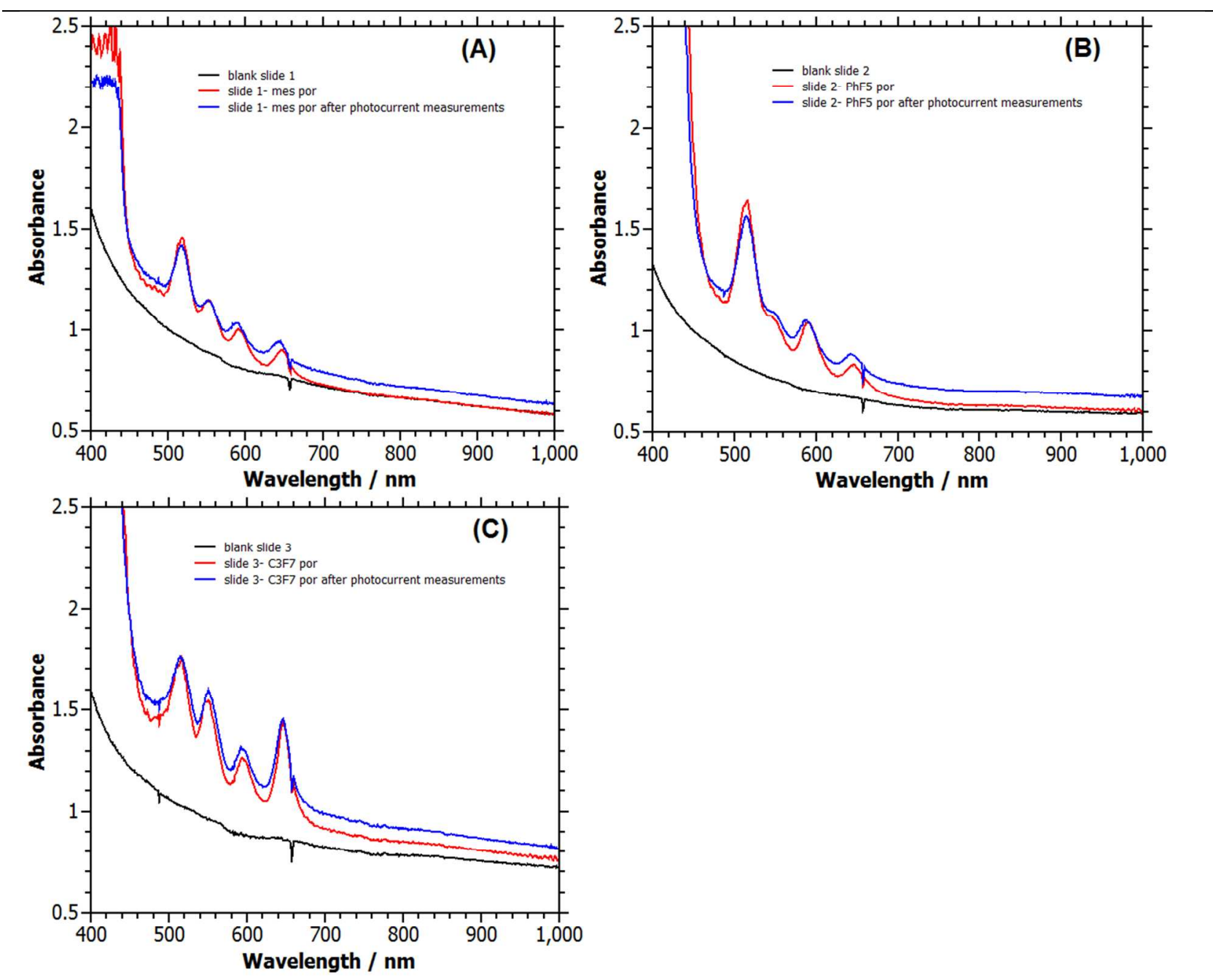

Figure S8. Absorption of $\mathrm{SnO}_{2}-\mathrm{TiO}_{2}$ core-shell slides loaded with 5 (A), 1 (B) and $\mathbf{6}$ (C) before and after photocurrent measurements 


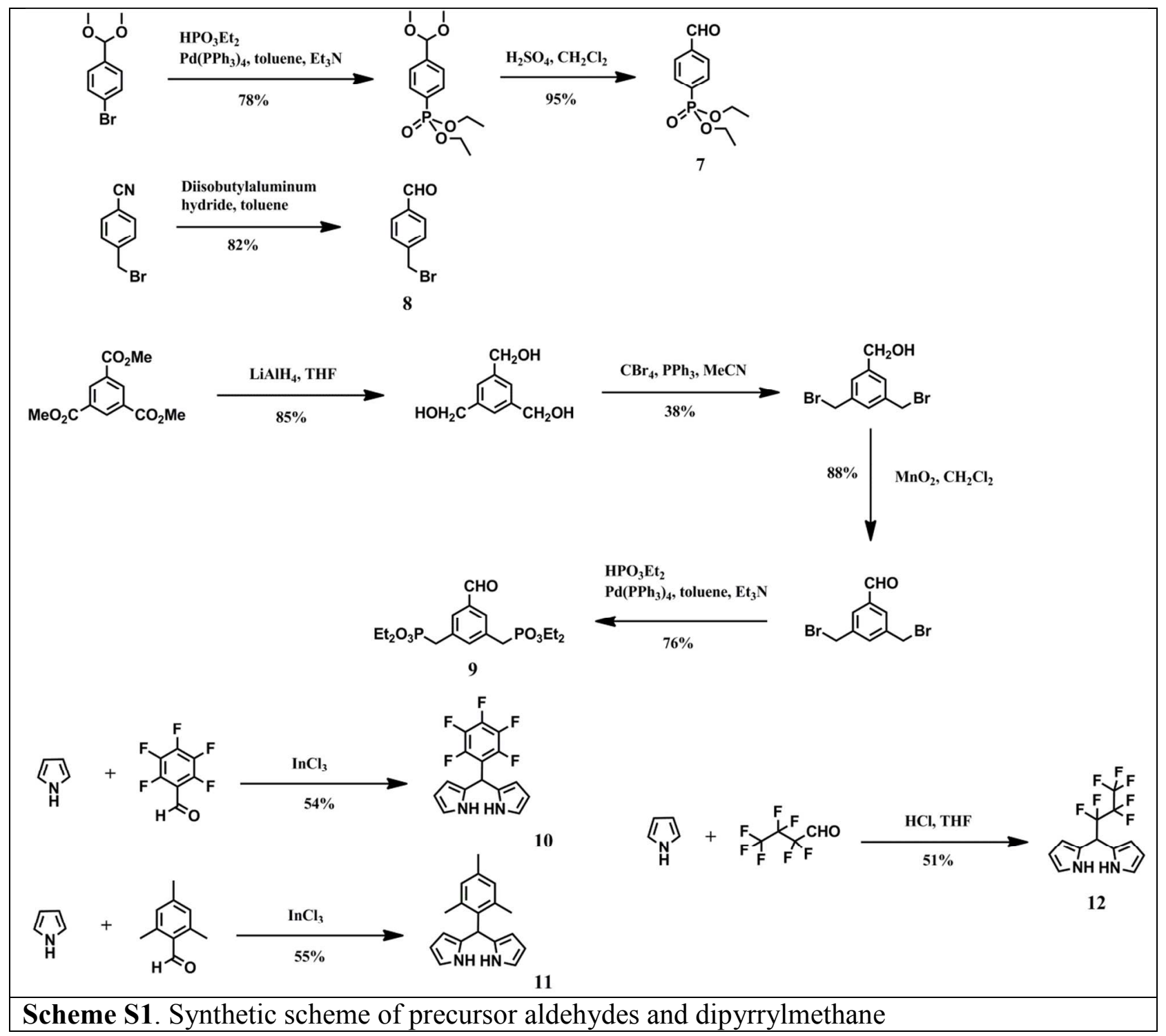




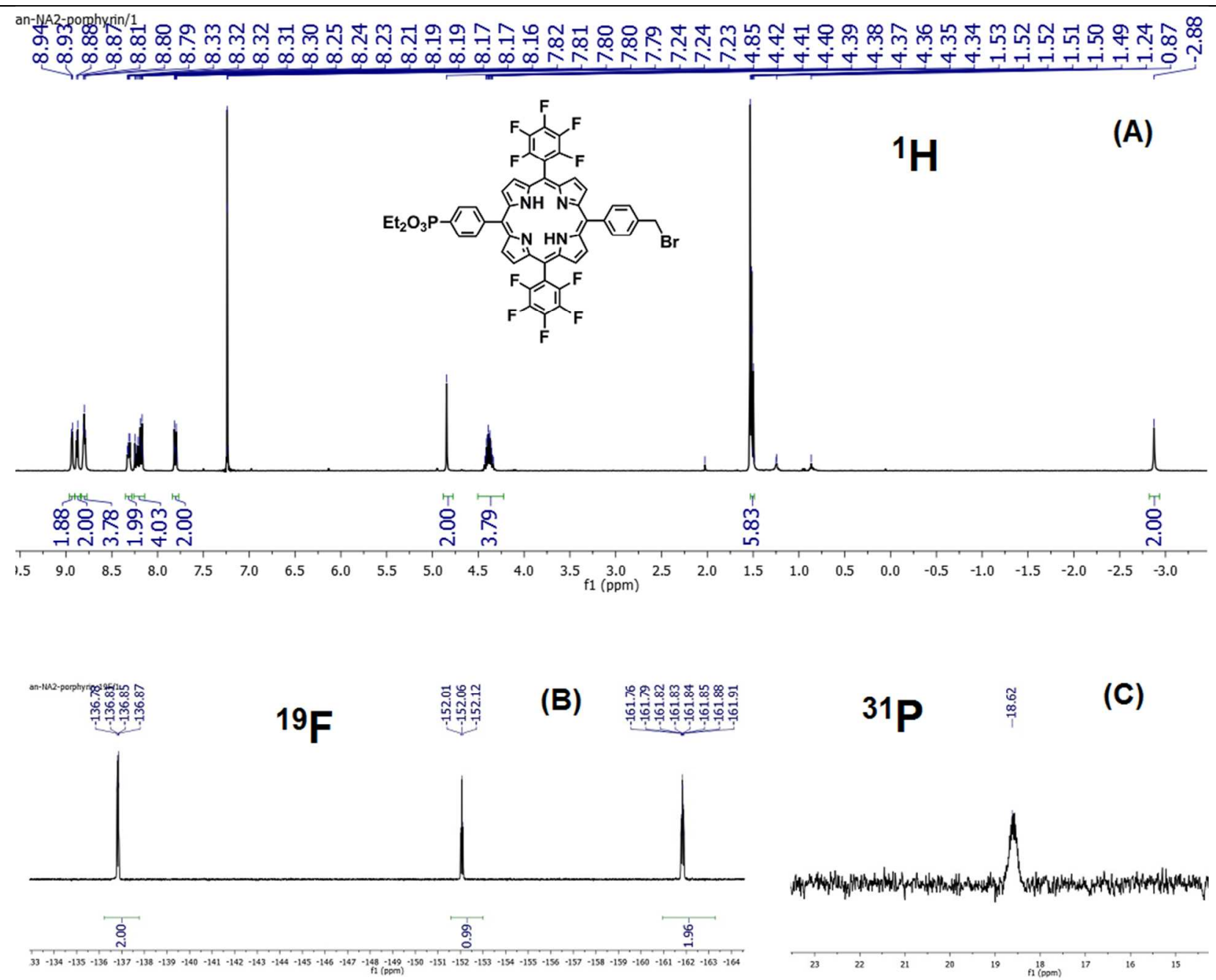

Figure S9. ${ }^{1} \mathrm{H}(\mathrm{A}),{ }^{19} \mathrm{~F}(\mathrm{~B})$ and ${ }^{31} \mathrm{P}(\mathrm{C}) \mathrm{NMR}$ of $\mathbf{3 E}$ in $\mathrm{CDCl}_{3}$ 


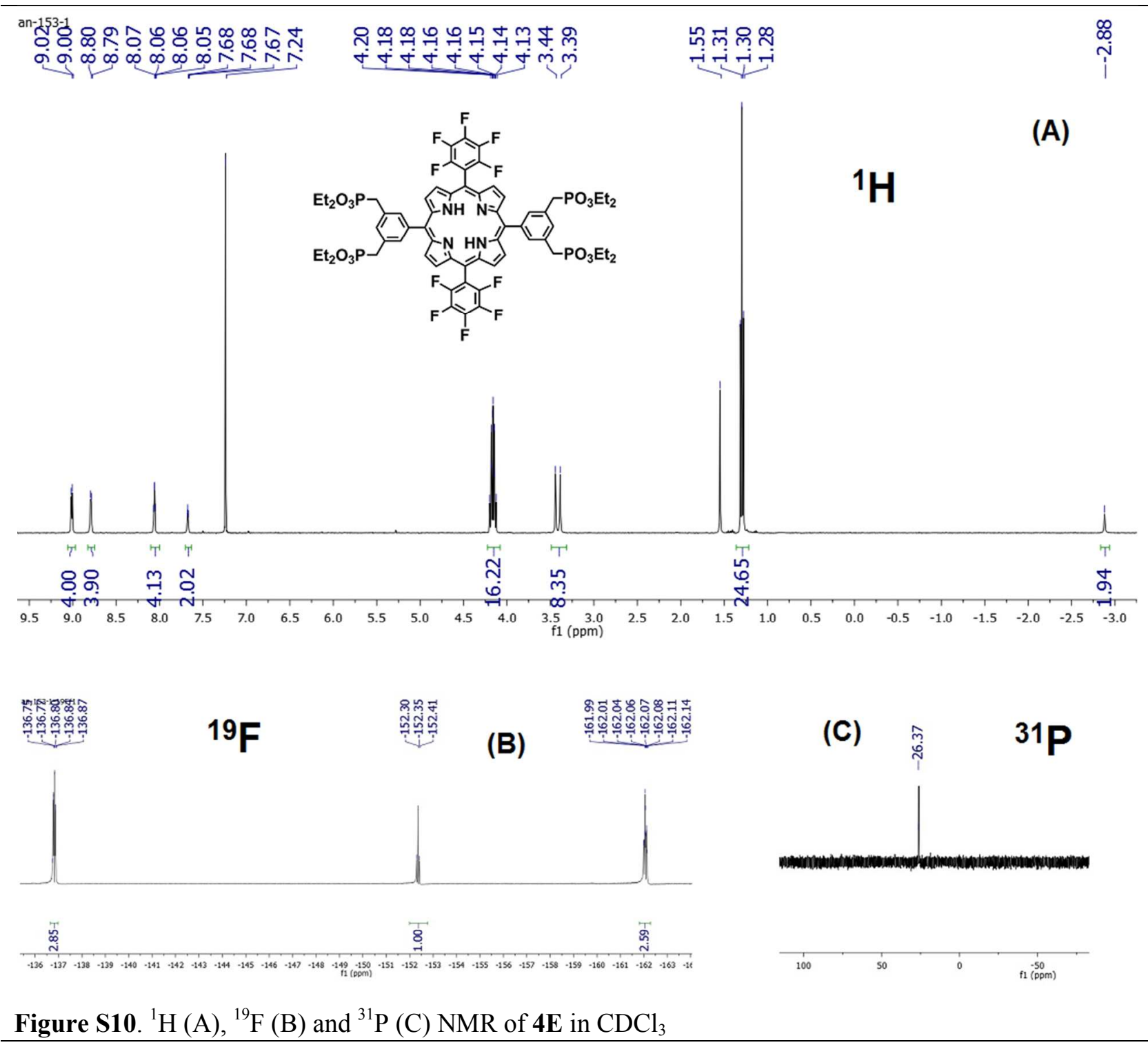




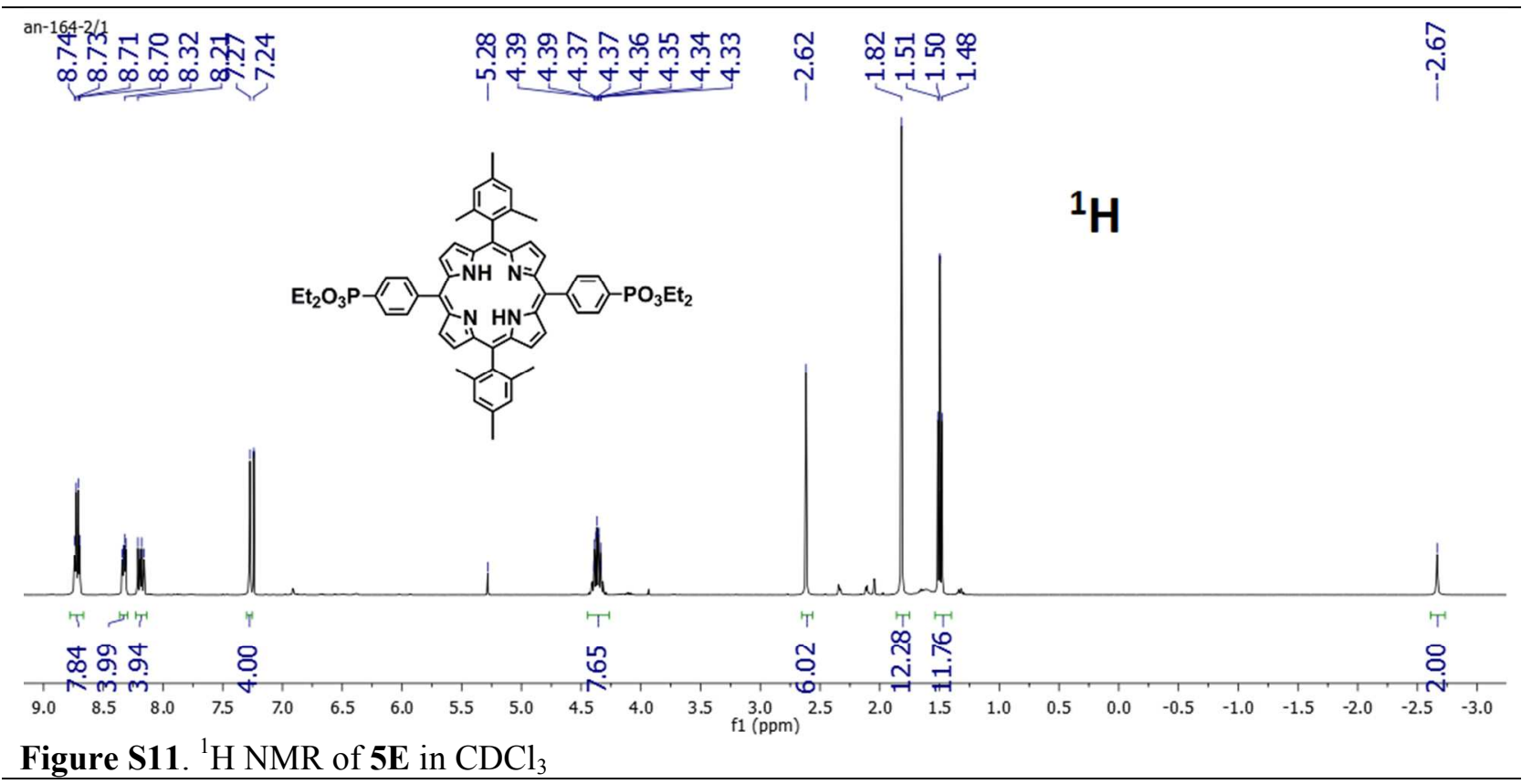




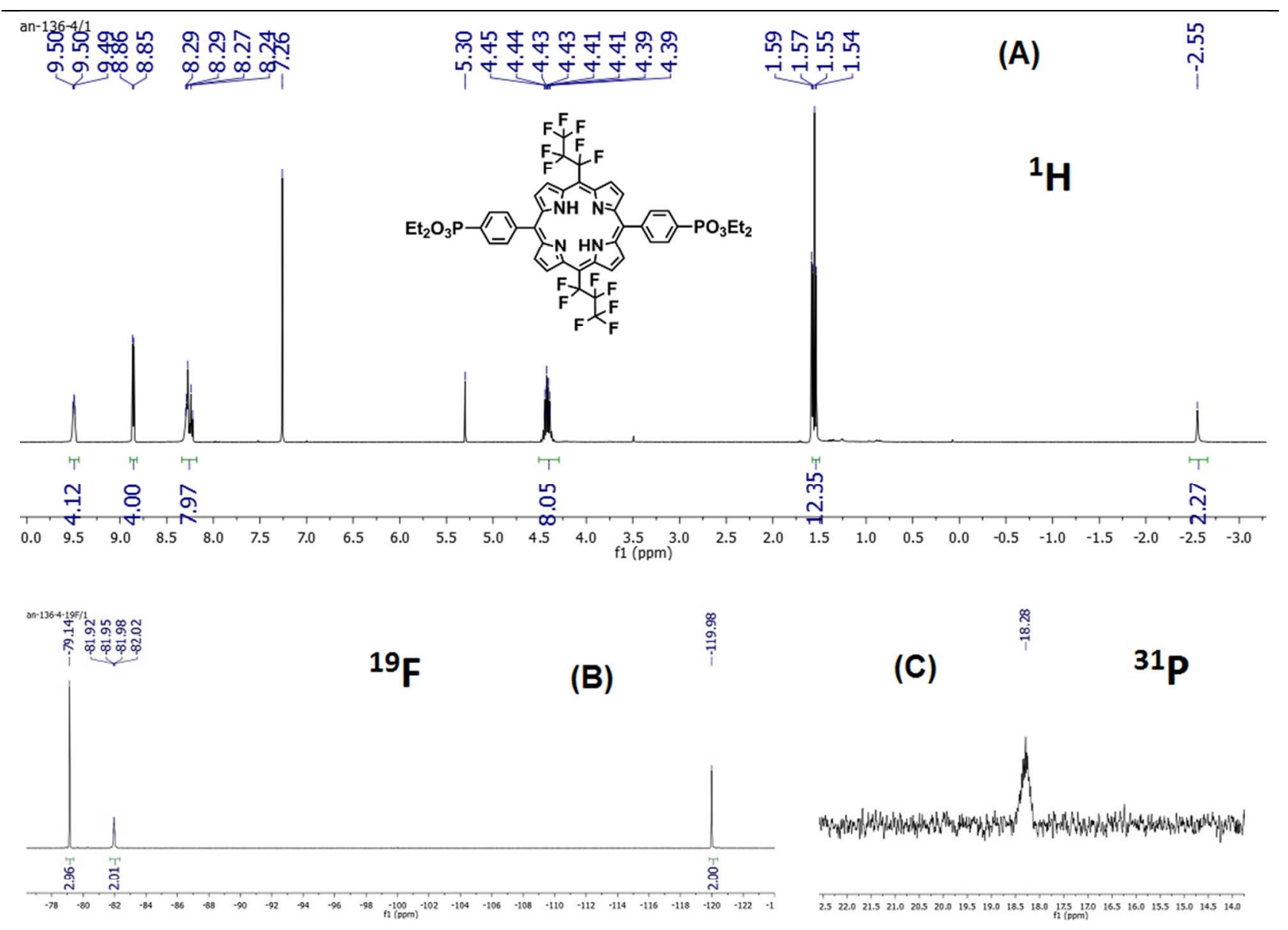

Figure S12. ${ }^{1} \mathrm{H}(\mathrm{A}),{ }^{19} \mathrm{~F}(\mathrm{~B})$ and ${ }^{31} \mathrm{P}(\mathrm{C}) \mathrm{NMR}$ of $\mathbf{6 E}$ in $\mathrm{CDCl}_{3}$ 


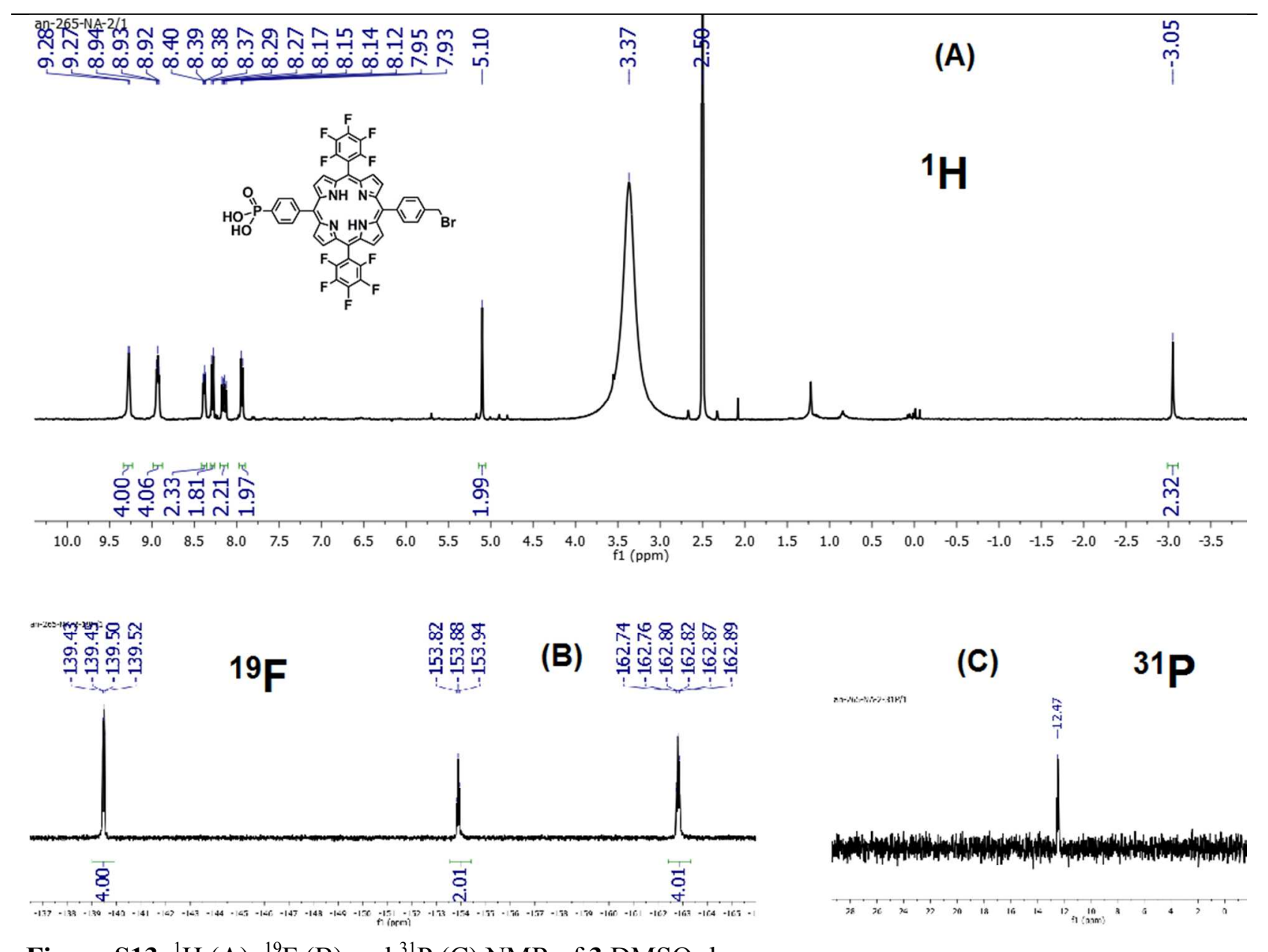

Figure S13. ${ }^{1} \mathrm{H}(\mathrm{A}),{ }^{19} \mathrm{~F}(\mathrm{~B})$ and ${ }^{31} \mathrm{P}(\mathrm{C}) \mathrm{NMR}$ of $\mathbf{3} \mathrm{DMSO}^{\mathrm{d}} \mathrm{d}_{6}$ 


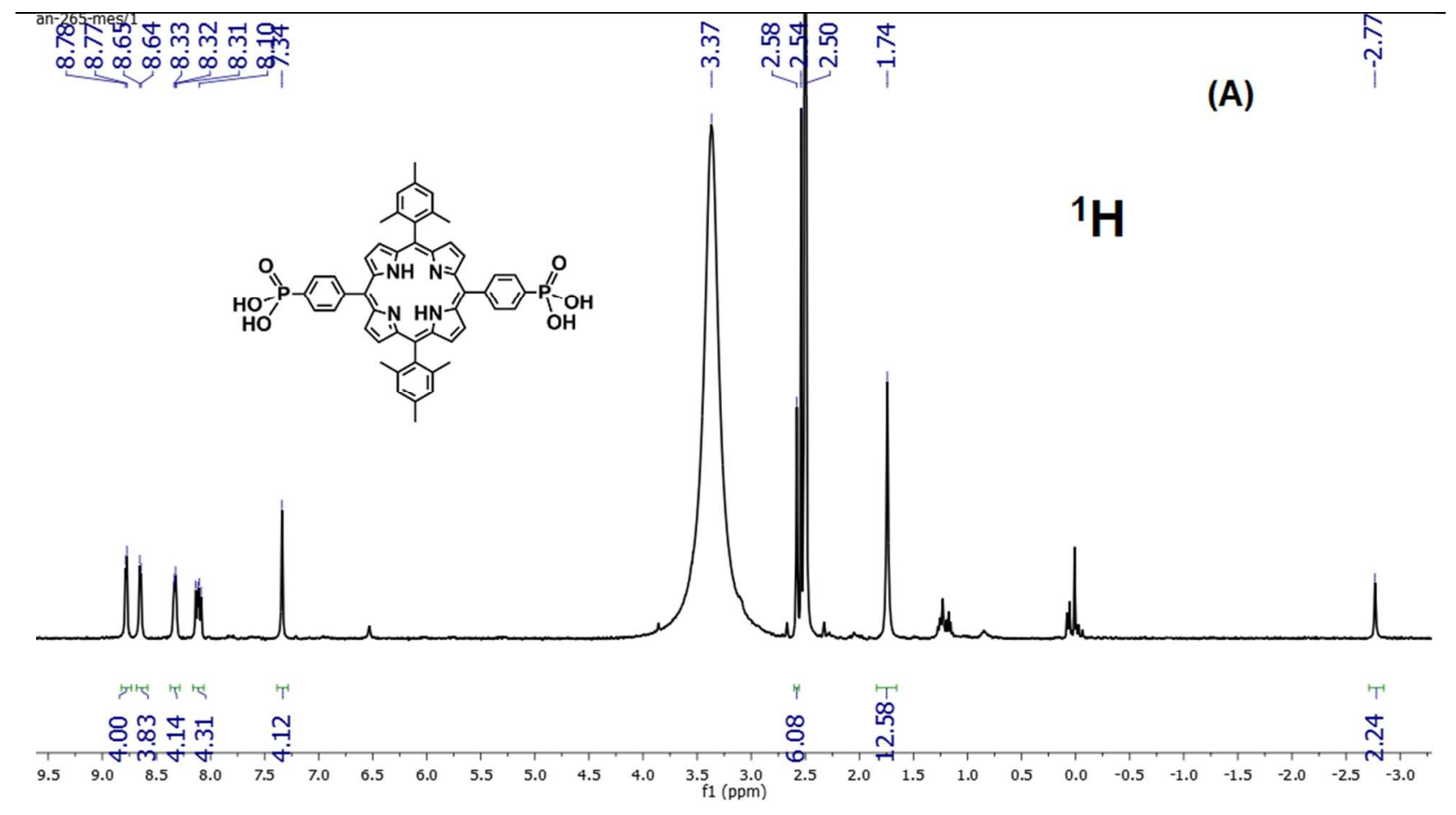

(B)

an-265-mes-31P/1

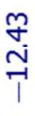

31P

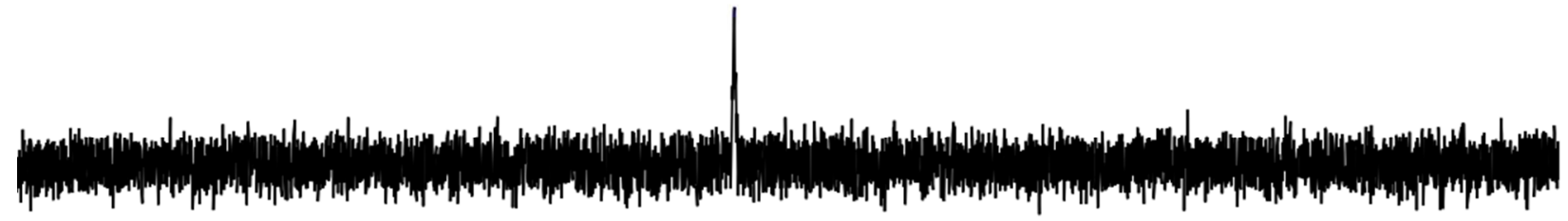

\begin{tabular}{llllllllllllllllllllllll}
\hline & 1 & 55 & 50 & 45 & 40 & 35 & 30 & 25 & 20 & 15 & 10 & 10 & 0 & -5 & -10 & -15 & -20 & -25 & -30 & -35 & -40
\end{tabular}

Figure S14. ${ }^{1} \mathrm{H}(\mathrm{A})$ and ${ }^{31} \mathrm{P}(\mathrm{B}) \mathrm{NMR}$ of 5 DMSO-d 6 

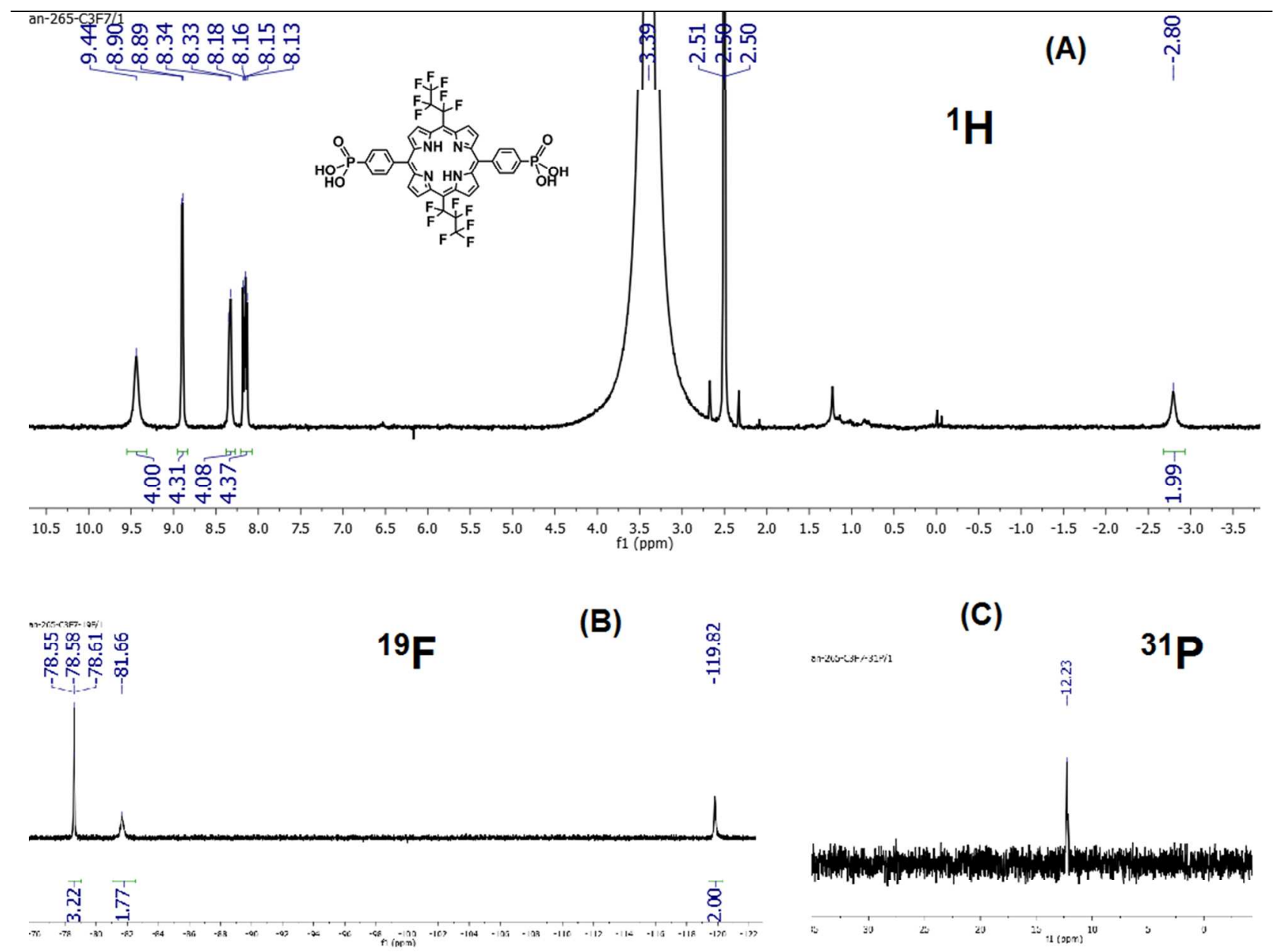

(C)

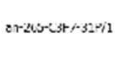

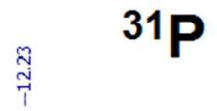

Figure S15. ${ }^{1} \mathrm{H}(\mathrm{A}),{ }^{19} \mathrm{~F}(\mathrm{~B})$ and ${ }^{31} \mathrm{P}(\mathrm{C}) \mathrm{NMR}$ of 6 in DMSO-d 6 